\title{
A PILOT STUDY COMPARING PLAYFULNESS AND THE ENVIRONMENTAL SUPPORT OF PLAY IN PRESCHOOL CHILDREN IN DIFFERENT SOCIO-ECONOMIC SETTINGS IN SOUTH AFRICA
}

\author{
J. Freeme, N. Ehlers, K.-L. Hoatson, R. Volker \\ Occupational Therapy, University of the Witwatersrand, Johannesburg, South Africa
}

Background and aims: Play is a major constituent of a child's development in physical, mental, social and emotional aspects. Environment has a significant effect on playfulness, and the research aimed at investigating whether there is a difference in playfulnes and environmental support in children in advantaged and disadvantaged settings in South Africa.

Methods: Playfulness and environmental support of play in preschool children in advantaged and disadvantaged settings was compared using the Test of Playfulness and the Test of Environmental Supportiveness.

A random sample of 30 children from six conveniently situated and government accredited care centres was selected. The children were normally developing and between the ages of 36 and 59 months.

Results: No statistically significant difference was found in playfulness between the two groups and the environmental supportiveness was found to be adequate in both settings.

Conclusions: Increased resources do not necessarily result in better environmental supportiveness and playfulness.

Both disadvantaged and advantaged settings were shown to be supportive, but there were also pressors in each setting which affected the children's approach to play.

The availability of resources did not affect the children's playfulness, but rather impacted on the type of age appropriate play they engaged in.

Normally developing children attending care centre environments daily are able to adapt to these environments despite the lack of or difference in resources to what they are used to in their home environments.

Access to these care centres in South Africa should be increased to allow all children to play in supportive environments. 